\title{
Preliminary assessment of Geant4 HP models and cross section libraries by reactor criticality benchmark calculations
}

Cai, Xiao-Xiao ; Llamas-Jansa, Isabel ; Mullet, Steven ; Hval, Sverre ; Klinkby, Esben Bryndt; Kittelmann, Thomas ; Kanaki, Kalliopi ; Hall-Wilton, Richard ; Hauback, B. C.

\section{Published in:}

Proceedings of 2013 IEEE Nuclear Science Symposium and Medical Imaging Conference (NSS/MIC)

Link to article, DOI:

10.1109/NSSMIC.2013.6829560

Publication date:

2013

Document Version

Publisher's PDF, also known as Version of record

Link back to DTU Orbit

\section{Citation (APA):}

Cai, X-X., Llamas-Jansa, I., Mullet, S., Hval, S., Klinkby, E. B., Kittelmann, T., Kanaki, K., Hall-Wilton, R., \& Hauback, B. C. (2013). Preliminary assessment of Geant4 HP models and cross section libraries by reactor criticality benchmark calculations. In Proceedings of 2013 IEEE Nuclear Science Symposium and Medical Imaging Conference (NSS/MIC) IEEE. https://doi.org/10.1109/NSSMIC.2013.6829560

\section{General rights}

Copyright and moral rights for the publications made accessible in the public portal are retained by the authors and/or other copyright owners and it is a condition of accessing publications that users recognise and abide by the legal requirements associated with these rights.

- Users may download and print one copy of any publication from the public portal for the purpose of private study or research.

- You may not further distribute the material or use it for any profit-making activity or commercial gain

- You may freely distribute the URL identifying the publication in the public portal 


\title{
Preliminary assessment of Geant4 HP models and cross section libraries by reactor criticality benchmark calculations
}

\author{
Xiao-Xiao Cai, Isabel Llamas-Jansa, Steven Mullet, Sverre Hval, Esben Klinkby, \\ Thomas Kittelmann, Kalliopi Kanaki, Richard Hall-Wilton, Bjrn C. Hauback
}

Geant4 [1] is an open source general purpose simulation toolkit for particle transportation in matter. Since the extension of the thermal scattering model in Geant4.9.5 and the availability of the IAEA HP model cross section libraries, it is now possible to extend the application area of Geant4 to reactor modelling. Before version 9.5, Geant4 HP thermal scattering model (i.e. the $S(\alpha, \beta)$ model ) supports only three bounded isotopes, namely, $\mathrm{H}$ in water and polyethylene, and $\mathrm{C}$ in graphite. Newly supported materials include $\mathrm{D}$ in heavy water, $\mathrm{O}$ and $\mathrm{Be}$ in beryllium oxide, $\mathrm{H}$ and $\mathrm{Zr}$ in zirconium hydride, $\mathrm{U}$ and $\mathrm{O}$ in uranium dioxide, $\mathrm{Al}$ metal, Be metal, and $\mathrm{Fe}$ metal. The native HP cross section library G4NDL does not include data for elements with atomic number larger than 92. Therefore, transuranic elements, which have impacts for a realistic reactor, can not be simulated by the combination of the HP models and the G4NDL library. However, cross sections of those missing isotopes were made available recently through the IAEA project "new evaluated neutron cross section libraries for Geant4" [2].

In this work, we assessed the performance of the combination of HP models and the IAEA new HP model libraries by reactor criticality calculation. The Gean 4 thermal scattering model was enabled in all cases.

The power iteration method has been used in this

Figure 1: Geant4 simulated core specified in LEUCOMP-THERM-001 case KRITZ 2:1 at $248.5{ }^{\circ} \mathrm{C}$

work. A $K_{e f f}$ estimator similar to the collision estimator in MCNP has been implemented in Geant4.9.5.p02. In the simulations, fission reactions were treated as capture reaction. Secondary neutrons from fission reactions were removed from current simulation cycle. But their histories ( i.e. position, direction and energy) were recorded to be used as the primary source particles in the next cycle. At the beginning of a new cycle, a constant number of neutrons were initialised by randomly sampling the histories in the last cycle. A number of inactive calculation cycles were performed until the $K_{\text {eff }}$ and fission distribution were converged. $K_{\text {eff }}$ were accumulated in the following active simulation cycles. Calculation will 
Table I: Comparisons of benchmark-model and calculated $K_{\text {eff }}$

\begin{tabular}{ccccccc}
\hline benchmark ID & case & \multicolumn{2}{c}{ benchmark model } & \multicolumn{2}{c}{ Geant4 calculated $K_{\text {eff }}$} \\
& & $K_{\text {eff }}$ & uncertainty & ENDF/VII.0 & JEFF-3.1 & JENDL-4.0 \\
\hline HEU-MET-T-FAST-069 & 1 & 0.9994 & 0.0004 & 0.99916 & & \\
HEU-MET-FAST-059 case 1 & 2 & 0.9929 & 0.0028 & 0.99221 & & \\
HEU-MET-FAST-059 case 2 & 3 & 0.9952 & 0.0016 & 0.99624 & & 1.99999 \\
LEU-MET-THERM-006 case 20 & 4 & 1.0000 & 0.0018 & 1.00016 & 0.99983 & 1.00109 \\
LEU-MET-THERM-006 case 24 & 5 & 1.0000 & 0.0018 & 1.00162 & 1.00123 & 0.99864 \\
LEU-MET-THERM-006 case 28 & 6 & 1.0000 & 0.0018 & 1.00356 & 1.00448 & 1.00318 \\
LEU-COMP-THERM-001 KRITZ 2:1 19.7C & 7 & 1.0000 & 0.0008 & 1.00051 & 0.99984 & 0.06417 \\
LEU-COMP-THERM-001 KRITZ 2:1 248.5C & 8 & 1.0000 & 0.0008 & 0.96418 & \\
LEU-COMP-THERM-007 Case 1 & 9 & 1.0000 & 0.00144 & 1.00520 & & \\
LEU-COMP-THERM-007 Case 2 & 10 & 1.0000 & 0.00081 & 1.00739 & & \\
LEU-COMP-THERM-007 Case 3 & 11 & 1.0000 & 0.00072 & 1.00638 & & \\
\hline
\end{tabular}

stop when the statistical error is lower than a satisfied level. Inactive and active cycles are 200 and 800 in this work, respectively. 10,000 neutrons are simulated in each cycle. The $1 \sigma$ uncertainties in all calculations are $0.035 \%$ (i.e. $35 \mathrm{pcm}$ ).

A total of 11 benchmark cases have been selected to calculate from the International Criticality Safety Benchmark Evaluation Project (ICSBEP) handbook. Simulated cases include high enriched $U$ metal fast neutron benchmark (HEU-MET-FAST-059 and HEU-MET-FAST-059), low enriched U metal thermal neutron benchmark (LEUMET-THERM-006), low enriched UO2 thermal neutron benchmark (LEU-COMP-THERM-007), and low enriched UO2 thermal neutron high temperature benchmark (LEU-COMP-THERM-001).

Calculated $K_{e f f}$ for case 1 to case 7 closely agree with benchmark $K_{\text {eff }}$. Different libraries used in case 4 to 6 showed very good consistency. However, Geant4 overestimated the $K_{\text {eff }}$ in case 9 to case 11 up to $739 \mathrm{pcm}$; and significantly underestimated the $K_{\text {eff }}$ in case 8 by about $3.6 \%$.

Indicated by Mendoza et. al. [2], Geant 4 thermal scattering model can behave differently than the $S(\alpha, \beta)$ model in MCNPX. We are now comparing these two models, and investigating if it is necessary to implement a new thermal scattering physics model based on ACE format files (http://www-nds.iaea.org/indltsl/) which is the standard cross section library format in MCNPX. Treatment of cross section Doppler effect in Geant4 will also be examined in the near future. More results will be presented in the conference.

\section{REFERENCES}

[1] S. Agostinelli et al., "Geant4-a simulation toolkit," Nucl. Instrum. Meth. A, vol. 506, no. 3, pp. 250 - 303, 2003.

[2] E. Mendoza et al., "New evaluated neutron cross section libraries for the GEANT4 code," IAEA INDC(NDS)0612, Tech. Rep., 2012. [Online]. Available: http://wwwnds.iaea.org/publications/indc/indc-nds-0612/ 